\title{
Improving the Safety Performance of Nigeria Construction Workers: A Social Ecological Approach
}

\author{
Peter Uchenna Okoye \\ Department of Building, Nnamdi Azikiwe University, Nigeria \\ *Corresponding Author: pu.okoye@unizik.edu.ng
}

Copyright $\odot 2016$ by authors, all rights reserved. Authors agree that this article remains permanently open access under the terms of the Creative Commons Attribution License 4.0 International License

\begin{abstract}
This study applied the principles of social ecological model in developing a safety performance improvement framework in Nigeria construction industry. When the data collected through questionnaires distributed to the construction workers were statistically analysed using Pearson Product Moment correlation, the study found that safety behaviour intervention factors were positively correlated with safety performance. The correlation coefficient (r) ranges from 0.9713 (for community attributes) to 0.9991 (for interpersonal attributes), all of which were statistically significant at 5\% significance level and the degree of freedom of 3 (i.e. $\mathrm{p}<0.05$ in all cases). The coefficient of determination also ranges from $94.34 \%$ (for community attributes) to $99.82 \%$ (for interpersonal attributes). This represented the amount of safety performance improvement that would be achieved when behaviour intervention were positively applied, and translated to the percentage of accident reduction on site. Based on this result, social ecological model of safety performance improvement (SEM-SPI) framework was developed. The framework involved four implementation strategic steps through which it could be applied. This framework would be used to model the behaviour of construction workers towards behaving safely. The study recommended a practical application of the framework so as to improve the safety performance of construction workers.
\end{abstract}

Keywords Construction, Safety Behaviour Intervention, Safety Performance, Social Ecological Model, Workers

\section{Introduction}

The construction industry is no doubt the backbone of economic and social development of every nation. Through its forward and backward linkages it connects all other sectors of the economy and serves as the rallying point for national development. For instance, at 2010 constant basic price, its contribution to the Nigeria Gross Domestic Product (GDP) was $2.88 \%$ in $2010 ; 3.31 \%$ in $2011 ; 3.05 \%$ in 2012 ; $3.59 \%$ in $2013 ; 3.82 \%$ in 2014 ; and $3.88 \%$ in 2015 [1-3]. In 2012, the industry contributed about $\$ 121,900.86$ million
Naira of the Gross Fixed Capital Formation; and employed $6,913,536$ personnel excluding the casual workers [1]. When compared against other subsectors of the Nigeria economy, the industry ranked $7^{\text {th }}$ in the contribution to GDP in 2015 despite separated from the real estate sector.

Despite its huge significance, the construction industry is still facing untold challenges especially in the developing countries like Nigeria [4-7]. In terms of safety performance however, the construction industry has performed abysmally. The construction industry is one of the most hazardous industries due to the unique nature of its products and the processes involved in it. It is one of the industries with very high accident rate. Hinze [8] infers that when compared with other labour intensive industries, construction industry has historically experienced a disproportionately high rate of disability injuries and fatalities for its size. Janackovic, Savic and Stankovic [9] accept that these represent a significant social and economic burden on individuals, employers, and society. As a complex, dynamic and challenging sector, the construction workforce, as a whole, comprises a diverse mix of races, socio-economic groups and cultures [10] which makes the construction process more challenging. Although dramatic improvements have taken place in recent decades [11], Alkilani, Jupp and Sawhney [12] argue that the safety record in the construction industry continues to be one of the poorest, thus, continues to hinder performance improvement. Mouleeswaran [13] also agrees that construction still accounts for a disproportionate number of occupational related fatalities despite recent efforts to improve site safety. Correspondingly, Sousa, Almeida and Dias [14] contend that the rate of accidents is still the highest in the construction industry despite the substantial improvements achieved in safety through the years. In Saudi Arabia for instance, the construction industry is considered a major contributor to work accidents [15]. Mouleeswaran [13] further argues that the construction workers are more prone to accidents as the industry is considered one of the most hazardous industrial sectors. To clearly underscore how pathetic this situation is, a brief background scenario of the global construction safety report and that of Nigeria is provided.

\subsection{Background Scenarios}


Globally, poor performance in the construction industry accounts for more than 100,000 fatalities annually, equating to approximately $30-40 \%$ of the world's work related fatal injuries [16,17]. Occupational Safety \& Health Administration (OSHA) [18] reports that every day more than 12 workers die on the job (more than 4,500 a year), and every year, more than 4.1 million workers suffer a serious work-related injury or illness. Almost 160 million people have work-related diseases; and in one third of these cases, the disease causes a loss of four or more working days [19]. The industry alone produces $30 \%$ of all fatal industrial accidents across the European Union (EU), yet it employs only $10 \%$ of the working population [20]. According to the methodology adopted by the United States Occupational Safety \& Health Administration (OSHA), the estimated value of each life lost is $\$ 8.7$ million, therefore, if one takes into account the number of deaths at work $(4,547)$ reported by the Bureau of Labour Statistics for the year 2010, the estimated annual cost is almost $\$ 40$ billion [18]. Che Hassan, Basha and Hanafi, [21] also report that the construction industry accounts for $22 \%$ of all fatal accidents in The United States of America (USA).

In other developed countries such as Japan, United Kingdom (UK), Singapore, Australia and Ireland, accidents still occur on construction site. Bomel [22] notes that in Japan, construction accidents account for $30 \%-40 \%$ of the overall industrial accidents, with the total being $50 \%$ in Ireland and $25 \%$ in the United Kingdom UK. Recent study conducted on health and safety in construction sector in Great Britain [23], shows that annually between 2011/12 and $2014 / 15$ around $69,0000(3.1 \%)$ of workers in the construction sector in Great Britain were suffering from an illness that they believe was caused or made worse by their work in the sector. Between 2012/13 and 2014/15 annually, around 65,000 (3\%) construction workers in Great Britain sustained an injury at work. Around a quarter of these cases resulted in absence from work of over 7-days. There were 35 fatal injuries to workers in the construction sector in 2014/15, around $20 \%$ lower than the five year average for 2010/11-2014/15 [23]. This brings the total number of fatal injuries to workers in the sector over the last five years to 217 . The worker fatal injury rate in the construction sector $(1.62$ per 100,000 workers) is over 3.5 times the average rate across all industries ( 0.46 per 100,000 workers). These resulted to loss of 1.7 million working days [23] even though there has been a downward trend in the rate of fatal injury over the latest 20 -year time period and more recently (since 2008/09) the trend is less clear [24].

While Singapore has made significant improvements in putting in place a comprehensive OSH framework that includes strong legislation, policies, a sound structure and functional systems, there are still significant gaps when benchmarked against leading countries in OSH [25]. Asanka and Ranasinghe [26] concur that accident still happens at the construction sites in Singapore and even at increasing rate when compared with the global benchmark. Likewise, Hosseini, Maghrebi and Rameezdeenc [27] found that though the newly-introduced regulation in South Australia has had a positive effect in reducing the number of accidents on construction sites accidents still occur.

In the developing countries also, the rate of construction accidents are even higher. For instance, the total number of reported work accidents in 2014 in Saudi Arabia was about 69,241 accidents [28]. The construction industry accounted for $51.35 \%$ of these accidents [28]. This high percentage could be due to many factors related specifically to the construction industry, e.g., construction sites are known for being dynamic with a constant changing environment $[14,29,30]$. Even though construction labour accounts for about $7.1 \%$ of the labour force in Jordan, accidents in the construction industry account for about $10.5 \%$ of incidents [31]. Somasundaraswaran, Brammananda, Akeel and Rajakumar [32] show that in Sri Lanka, about $25 \%$ of the total labour accidents were from the construction industry, and the fatal accident rates in construction industry were higher than other industries.

In South Africa, Uganda and other African countries [33] the situation is not better neither. Smallwood, Haupt and Shakantu [34] report that while it is acknowledged that many industry associations and professional societies, contracting organisations and others have made significant efforts to improving health and safety within the construction industry, construction health and safety is not improving commensurately. Notably, construction continues to contribute a disproportionate number of fatalities and injuries relative to other industrial sectors, and there continues to be high levels of non-compliance with health and safety legislation generally, and specifically the construction and other health and safety regulations in South Africa. Secondly, construction health and safety statistics provided by the Department of Labour (DoL) covering the period 2004/05 to $2007 / 08$ showed a sharp rise in accidents up to $2007 / 08$; to around 160 fatalities and around 400 non-fatal accidents (i.e. temporary or permanent disablements). These statistics reportedly include the Federated Employers Mutual Assurance Company Limited (FEMA) and statistics (but excluding motor-vehicle accidents) [34].

In Nigeria, the situation is even more pathetic. Dearth of reliable accident records on construction site makes the situation more pitiable. Abubakar [35] argues that workplaces in some countries like UK have become safer over the years unlike the situation in Nigeria. According to Hämäläinen, Saarela and Takala [36] the annual work-related death rate of Nigeria stood at about 24 fatalities per 100,000 employees, which is one of the highest in the world. This is based on the data available in 2003. A field study conducted by the Federal Ministry of Labour and Productivity Inspectorate Division (now the Federal Ministry of Labour and Employment) suggests that work-related fatalities are on the increase in Nigeria between 2002 and 2012 [37]. Also, a survey recently conducted by Abdulahi et al. [38] on the artisans working condition in the Nigerian construction industry in some states in Northern 
Nigeria claim that about $76.40 \%$ of the artisans have been involved in one form of accidents or the other on construction sites.

Notwithstanding, these reports have been argued to be grossly underreported and inaccurate across the globe. Matiko [39] argues that collection of data on injuries and diseases is inadequate in most countries. Nevertheless, available data indicated a frightening trend. In some of the countries where there are adequate data collection systems, most of the data are not fully comparable from one country to the next because of variations in definitions, recording and notification systems [24,39]. Reports from different countries on safety performance of construction industry show how precarious this situation is. Although procedures, regulations, and safety management systems (SMS) have reduced the incidence of occupational accidents, they still occur. Current methods have enjoyed some success however; these methods mostly address aspects of safety that are not behaviour-related [40]. Fleming and Scott [41] agree that these efforts have been very successful as large improvements in workplace safety have been achieved through improved hardware and design, and through improved safety management systems and procedures. While the improvement can be acknowledged in terms of low accident rates in the majority of safety critical industries, it does appear that they have reached a plateau and cannot provide further improvement. With this, Allegrante et al. [42] argue that such a reductionist perspective overlooks the importance of the psychological, environmental, and socio-cultural conditions as contributing factors to injury and its consequences, though injury prevention often is conceptualised as a biomedical construct.

\subsection{Purpose of the Study}

There is evident that efforts to improve the safety performance of construction workers are not sufficient to control the occurrence of unsafe acts at construction sites [43]. It has been argued that construction actors' behaviours account for most accidents and so understanding and being able to modify behaviour should be crucial to improving the occupational safety and health (OSH) performance of the industry [40]. Thus, since the frequency of technological failures in industry has diminished, the role of human behaviour has become more apparent. Safety experts estimate that $80-90 \%$ of all industrial accidents are attributable to 'human factors' [44]. To this end, Guo and Yiu [45] aver that the existing safety performance indicators in the construction industry had failed to capture the reality of safety. Guo and Yiu [45] further maintain that it may be inappropriate, and even dangerous, to use safety performance indicators that are selected based on the normative safety management system (SMS) approach as an evaluative tool to identify safety problems, offer solutions and measure safety performance; because managing safety in a proactive manner requires foresights, rather than hindsight. Therefore it seems likely that the most effective way to reduce workplace injury and accident rates even further and improve hazard management is to address the social and organisational factors that have an impact on safety [46]. The recognition of the importance of organisational and social factors in improving workplace safety is demonstrated by increased efforts to improve safety leadership, safety culture/climate, and employee safety behaviours [41].

Meanwhile there are three major approaches to safety improvement in organisations: safety management systems (SMSs); behaviour based safety (BBS) approaches; and safety culture change programmes [47]. These approaches are not mutually exclusive, and in fact, scholars argue that the most effective approach is to use a combination of all three [48]. Although Dejoy [48] suggests two dominant psychological approaches to improving workplace safety; (1) behavioural-based safety initiatives and (2) safety culture strategies, the two approaches are also different from each other and in many ways have opposing views about how to motivate employees to work safely. Notwithstanding the different strategies propose by the two approaches for organisations to enhance safety, there is evidence supporting the effectiveness of both behaviour-based [49] and safety culture [50] interventions. However, Wamuziri [51] suggests that future improvements in performance are likely to come not from more legislation or simply changes to management systems. According to Wamuziri [51] though rules, regulations and managements systems have their role to play in improving safety performance, on their own they are inadequate to bring about further major improvements in safety performance which are required in the industry. Thus, Wamuziri [51] hypothesises that a major cultural shift in attitudes is still required in the industry.

In response to the scenario above, Sherratt [52] argues that the problem with the construction industry lies with the people that operate within it. Therefore, increasing evidence suggests that public health and safety behaviour interventions that are based on social and behavioural science theories are more effective than those lacking a theoretical base [53]. Accordingly, it appears that some of the current systems can be revised to take into account factors that affect safety behaviour [40]. To this effect, Khosravi et al. [54] provided a good fit structural model that suggests that some social and organisational components share their influence on safety performance via the general component of safety climate. Nonetheless, improvement of safety performance in the construction industry especially in the developing countries still remains a subject of current debate. It is on this premise that this study argues that improvement of safety performance of construction industry lies on the application of social ecological theory in the industry which inadvertently will influence the behaviours of the industry players and stakeholders at all levels.

The argument above is substantiated by the fact that behaviour-based safety (BBS) has been instrumental in reducing accidents and increasing the overall safety performance in several industries $[55,56]$. It can also have a positive impact on productivity [55]. Cooper [57] even argues that the benefits of BBS outweigh its costs, which 
would suggest that there should be no reason why all construction organisations in Nigeria do not employ this strategy of reducing accidents. Notwithstanding, there is continuous degeneration of safety performance in the construction industry especially in the developing countries like Nigeria. It is in line with this scenario that Hovden, Albrechtsen and Herrera [58] call for a need for new theories, models and approaches to occupational accident prevention.

This study therefore is aimed at developing a framework for improvement of safety performance of Nigeria construction industry through the application of the principles of social ecological theory. Based on the fact that at different levels of nested structures including: individual, interpersonal, organisational, community environment and policy factors [59], the safety performance of construction workers is significantly influenced. In view of this, the study hypothesises that safety performance of construction workers is significantly influenced by different safety behaviour interventions at different levels of nested structures.

\section{Theoretical Framework}

Construction processes and products involve series of physical activities. However, physical activity behaviour and the factors influencing it is very complex [60]. Research suggests that the social, physical and policy environments impact on the ability or likelihood of individuals participating in physical activity. Human behaviour is difficult to change, especially in an environment that does not support change like in construction. In order to increase or improve the performance of construction activity, efforts need to focus not only on the behaviour choices of each individual but also on factors that influence those choices. World Health Organisation [61] reports that health behaviours, including physical activity participation, are thought to be improved when environments and policies support healthy choices, and individuals are motivated and educated to make those choices. Hence, educating people to make healthy choices when environments are not supportive will not be effective in making behavioural change.

Meanwhile, ecological and social ecological models of human behaviour have evolved over a number of decades in the fields of sociology, psychology, education and public health and focus on the nature of people's interactions with their environments [60]. Glanz, Rimer and Viswaneth [62] observe that among the major proponents of social ecological theory include: Urie Bronfenbrenner's Ecological Systems Theory [63], which focused on the relationship between the individual and the environment; Kenneth McLeroy's Ecological Model of Health Behaviours [64], which classified five different levels of influence on health behaviour, although this did not include physical environment, which is an essential element of a social ecological model of physical activity; and Daniel Stokols's Social Ecology Model of Health Promotion [65-67] identified the core assumptions which underpin the social ecological model. It is the works of these scholars and others that have been modified to evolve into what is referred to as the social ecological model [60].

The social ecological model helps to identify opportunities to promote participation in physical activity by recognising the multiple factors that influence an individual's behaviour. Efforts to change behaviour are more likely to be successful when the multiple levels of influence are addressed at the same time [60]. The social ecological model helps users to understand factors affecting behaviour and also provides guidance for developing successful programmes through social environments [53,68]. Social ecological models emphasise multiple levels of influence (such as individual, interpersonal, organisational, community, and public policy) and the idea that behaviours both shape and are shaped by the social environment $[64,69]$. The principles of social ecological models (of which several have been proposed) are consistent with Social Cognitive Theory concepts, which suggest that creating an environment conducive to change is important to facilitate adoption of healthy behaviours [70-72]. The social ecological model acknowledges that it takes a combination of both individual level and environmental/policy level interventions to achieve substantial changes in health behaviours, including physical activity behaviour [60].

Thus, social ecological models are used to provide a framework to understand the numerous factors and behaviours that enable or act as barriers to physical activity participation. Models are used to help us understand a specific problem in a particular setting or context. They help us to identify factors related to physical activity participation in specific populations therefore enabling the design of more effective interventions. The model suggests that there are multiple levels of influence, and that effective prevention and reduction programmes should address each of those levels. The model also serves as a reminder that individual knowledge is not sufficient for behaviour change; increasing knowledge, training skills and creating a supportive environment are all important components of behaviour change [73].

In the context of construction safety performance, the term intervention is used to describe safety behaviour strategy, programme or policy that is designed to have an impact on safety performance. Models are used to inform intervention development, implementation and evaluation. In this case, the influence of these factors is observed on the construction workers safety behaviours. For example, an individual's social environment of family, friends and workplace are embedded within the physical environment of geography and community facilities, which is in turn embedded within the policy environment of different levels of government or governing bodies [74]. This is to say that all levels of the social ecological model impact on the behaviour of the individual [66]. The social ecological model represents this concept as a series of overlapping circles, with each circle representing a different layer or component of the model (see figure 1). 


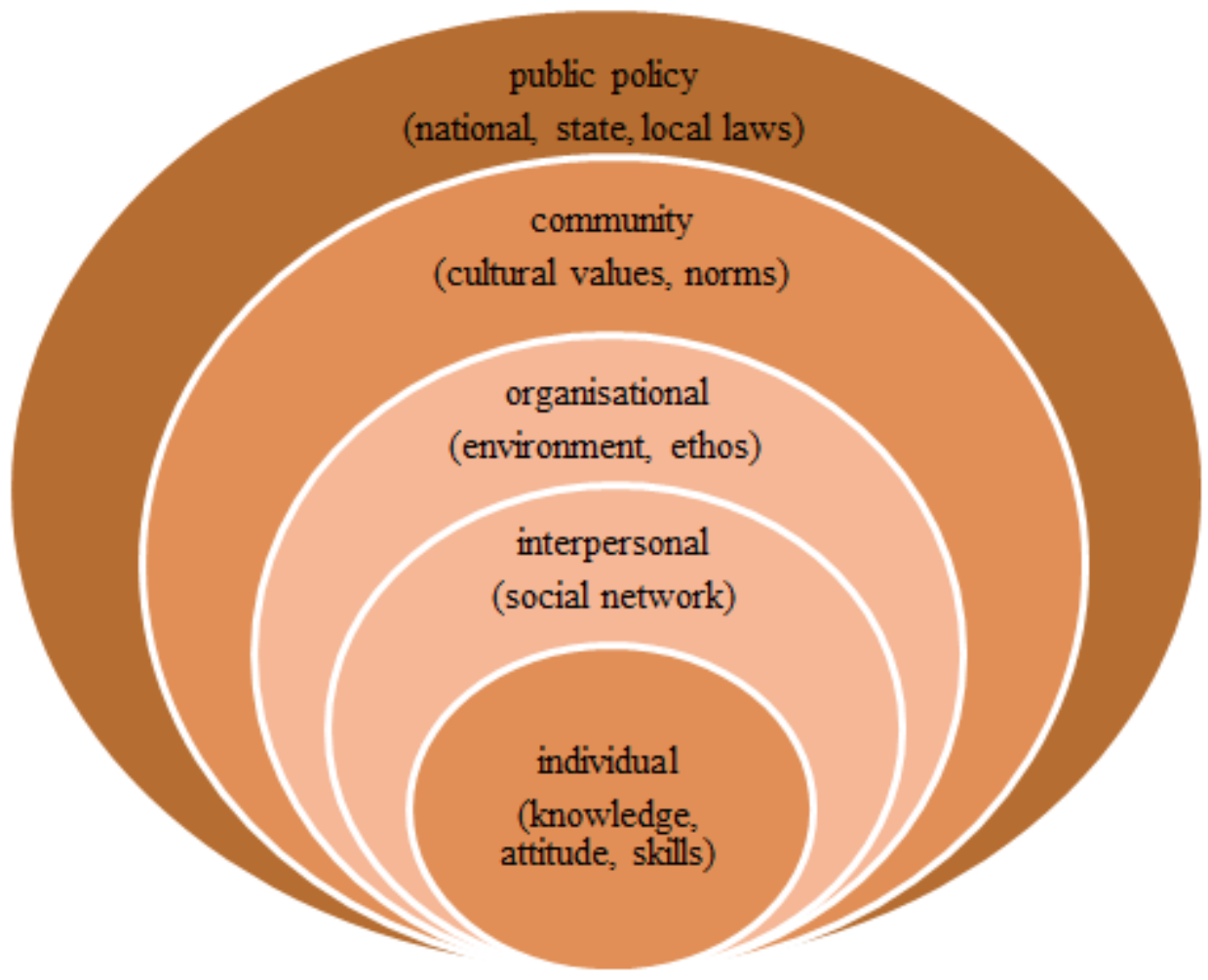

Figure 1. Social Ecological Model [64]

\subsection{The Main Constructs of Social Ecological Model (SEM)}

In its simplest form Callahan-Myrick [75] defines the social ecological model (SEM) as a graphic depiction of the ecological theory of a given health behaviour or outcome. It can provide a useful framework for achieving a better understanding of the many factors and barriers that impact health behaviours and outcomes, in this case safety performance of construction workers. The social ecological model helps to direct attention to broader political and environmental factors that shape individual and interpersonal characteristics of a person [76]. VCAA [60] observes that there are a number of versions of the social ecological model, which use slightly different classifications of environmental influences. Bronfenbrenner's work saw the influences on behaviour as a series of layers, where each layer had a resulting impact on the next level. He described these layers as being like a series of Russian dolls, where the innermost level represents the individual, which is then surrounded by differing levels of environmental influences [74].

Nevertheless, it is good to tailor the social ecological model to suit particular behaviours and population groups because intervention strategies would differ for each population and in each setting. Unfortunately, other theories needed to be integrated into multilevel frameworks, and empirical research to guide model development is limited [77].While acknowledging that applying a social ecological model to the design of interventions is challenging, Elder et al. [77] argue that the components of the social ecological model will remain the same and can be used in a range of populations, while the specific examples within each component will vary depending on the population group. In this case, the construction workers working on construction site are considered. For the purpose of this study, the five levels SEM of McLeroy et al. [64] are adopted, because the model addresses the peculiarity of construction industry setting. These levels are briefly discussed below.

\subsubsection{Individual (Intrapersonal) Level}

The first level of the SEM is the intrapersonal level. Lakhan and Ekúndayò [78] describe this as the central level of the social ecological model which encloses the individual. It identifies the biological and personal history factors that increase the likelihood of becoming performing safely. These factors can include knowledge, attitudes, and behaviours taking risks in addition to age, and gender [79]. This level includes personal factors or attributes that increase or decrease the likelihood of an individual being physically active. Individual factors which influence safety performance include: knowledge, attitudes, and behaviours, beliefs, perceived barriers, motivation, enjoyment skills (including fundamental motor skills and sports specific skills), abilities, disabilities or injuries, age, sex, level of education, socioeconomic status, employment status and self-efficacy. Strategies which bring change at the individual level tend to focus on changing an individual's knowledge, attitudes, behaviour and skills. They also include education and mentoring programmes. 
According to Allegrante et al. [42], the intrapersonal level involves the characteristics of the individual, that is, his or her knowledge, skills, life experience, attitudes, and behaviours as they interface with the environment and society. For Lakhan and Ekúndayò [78], the person interacts with objects and people in their intimate and immediate world. The individual's micro-system includes parents, siblings, spouse, friends, children and significant others involving very dynamic and active engagement and interactions. This is to say that at the personal level, individuals construct meaning and develop behaviours in relation to others and to larger collective ideals, shared symbols, and beliefs. Simultaneously, individuals influence their social ecology by controlling the cycling of resources and constructing norms, beliefs, and culture across multiple systems [59]. Having seen that the intrapersonal level, in the centre, is most related to an individual's behaviours and health beliefs; it is the most personal level of the model. As the levels move away from the centre, they tend to become less of a direct influence on health behaviour and begin to have a more indirect influence [80]. Although not all influences have equal impact on a workers safety behaviours and decisions, as can be seen from the model, they are all connected to an overall workers safety performance in some way [75].

\subsubsection{Interpersonal Level}

The interpersonal level examines the close relationships and influences that may directly affect the safety behaviours of construction workers. This includes the immediate physical environment and social networks in which an individual lives, including family, friends, peers, local facilities and services, and colleagues and co-workers $[42,78]$. VCAA [60] avers that the social environment has a significant influence on physical activity behaviour. For example, having someone such as a peer, family member or work colleague to be physically active that can impact on physical activity behaviour. In this case, the system may includes institutions, formal and informal bodies, religious institution (church, temple, mosque etc), school, club, office, work, union, informal support group, and volunteer organisation etc, with which the person is in close contact [78]. Summarily, interpersonal level involves persons and small groups with whom the at-risk people associate (family, friends) [81]. According to VCAA [60] the strategies which bring change at the social environment level include community education, support groups, peer programmes, workplace incentives and social marketing campaigns. These are used to promote positive community attitudes and awareness to participation in physical behaviour activity. However, Fleury and Lee [82] are of the opinion that the current social ecological frameworks acknowledge multiple levels of influence on the adoption and maintenance of physical activity rather than the traditional sole focus on intrapersonal factors.

\subsubsection{Organisational Level}

Organisational influences on health behaviour include formal and informal organisations as well as social institutions [64]. This involves commercial organisations, social institutions, associations, clubs, and other structures that have rules and regulations enabling them to have direct influence over the physical and social environments maintained within their organisation [42].These however, include specific social structures and organisations that does not contain individual, but affects an individual's immediate environment and their micro system. The individual does not play any role in constructing this system, but they experience direct impact on their mood and affect [78]. Richards, Riner and Sands [83] also note that people spend a majority of their lives in organisational settings including educational and occupational settings and these settings can have a strong impact on health related behaviours. Organisational level involves systems with a formal multi echelon decision process operating in pursuit of specific targets (schools, companies, professional associations) [81]. In view of this, McLeroy et al. [64] state that organisational characteristics such as the use of incentives, management and supervisor support changes in benefits, and changes in the structure of work may all be used to support behavioural changes.

\subsubsection{Community Level}

The community can be defined within geographical or political boundaries and may share demographic, cultural, ethnic, religious, or social characteristics, with its members having a sense of identity and belonging, shared values, norms, communication and helping patterns [42]. Environmental influences on health behaviour include relationships between community organisations, institutions, neighbourhoods, and community networks. These relationships can serve as positive change agents for health and safety promotion [83]. Community level involves collectives of people identified by common values and mutual concern for the development and well being of their group or geographic area (villages, neighbourhoods) [81]. To this end, this covers the larger society and culture in which an individual lives and interacts. Macro system plays a ubiquitous role including in developing and industrialised countries, across all socioeconomic status, ethnicity, and immigrant status. This system deals with the perception of general community that affects individual, family, school, and institutions [78].

\subsubsection{Public Policy Level}

These are larger systems, often defined along political boundaries, possessing the means to distribute resources and control the lives and development of their constituent communities [42]. This system considers cumulative experiences on a person, what they experience over the course of their lifetime [78]. These experiences include environmental events, as well as major transitions in life. It involves formal and informal rules (local, state and national laws and regulations). Policies, rules and regulations, political parties in action impact the individual and their 
micro system [78].

According to VCAA [60], this refers to legislation, regulatory or policy making actions that have the potential to affect physical activity. These are often formal legal actions taken by local, state or federal governments but also can be informal local policies or rules in settings such as workplaces. Policy may include: urban planning policies, construction policies, active transport policies, health and safety policies, environmental policies, workplace policies and funding policies. Meanwhile, developing the political will to implement policies promoting physical activity participation can sometimes be difficult, but [84] avow that strategies which align physical activity participation with priorities from other sectors can increase the chances of succeeding. Therefore, policy level involves larger systems possessing the means to control several aspects of the lives and development of their constituent subsystems (provinces, states, countries) [81].

Generally, Stokols [66] observes that the social ecological paradigm is rooted in certain core principles or themes concerning the interrelations among environmental conditions and human behaviour and wellbeing. There are four core principles upon the social ecological model is based $[60,66,85]$.

Multiple factors influence behaviours: There are multiple influences on specific health behaviours, including factors at the intrapersonal, interpersonal, organisational, community, and public policy levels [85]. Therefore efforts to change behaviour, including safety behaviour, should be based on the understanding of the interrelationship between the five levels of the social ecological model: individual, interpersonal, organisational, community and public policy. Safety performance interventions are more likely to be successful when they target multiple components of the social ecological model.

Environments are multidimensional and complex: Influences on behaviours interact across these different levels [85]. Social or physical environments can be described as containing a variety of features or attributes, such as the size, temperature, facilities and safety [66]. Environments can also be described in terms of their actual or perceived qualities. The variable nature of environments has a direct implication on the design of initiatives to promote safety performance.

Human environment interactions can be described at varying levels of organisation: Ecological models should be behaviour-specific; identifying the most relevant potential influences at each level [85]. Human interactions with the environment can occur at individual, small group, organisational, community or population levels. The SEM does not just focus on the individual but includes multiple levels of human interaction with environments [60]. The effectiveness of improving safety performance is enhanced when they target differing levels of the human-environment interaction.

The interrelationships between people and their environment are dynamic: Multi-level interventions should be most effective in changing behaviour [85]. There is a reciprocal relationship between people and their environments. The social, physical and policy environments influence the behaviour of the individual, while at the same time behaviour of the individual, group or organisation also impact on the wellbeing of their environments. The environment can control or set limits to the physical activity behaviour that occurs within it. Making a change in the environment can result in a modification of behaviour $[66,86]$.

\subsection{Application of Social Ecological Model (SEM) in Improving Safety Performance}

Glanz [68] argues that the most often mentioned theoretical model that has not been fully applied in research and practice is the Social Ecological Model; and then suggests that this promising model needs to better articulated, applied and evaluated. Recently, research has shown that SEM is majorly applied in the public and medical health research [42,59,77,78,87-92]. Elder et al. [77] observe that SEM is becoming more widely used in health behaviour research. According to Sallis et al. [87], SEM model found relevance in several health issues. However, it is apply across all health concerns. More so, the social ecological perspective has been used to develop "multilevel interventions" in order to modify health-related behaviour. Multilevel interventions can intervene at various levels and have different targets (i.e., objectives) at each of these levels [81]. Although the social ecological framework of behaviour change is rooted and mostly applied in the public health practice, its application in the construction industry practice is worthwhile because of continuous health and safety related challenges in the industry.

In applying social ecological theory to safety performance of construction workers, it should be understood that behaviours are shaped through a complex interplay of determinants at different levels. For example, safety behaviour activity is influenced by self-efficacy at the individual level, social support from family and friends at the interpersonal level, and perceptions of safety at the organisation and community levels, and relevant safety regulations at local, state and federal levels. Ecological models suggest that these multiple levels of influence interact across levels. For example, social support for welfare and health and safety facilities from co-workers and organisation may interact with the availability of such facilities at the worksite to lead to improve safety performance.

Traditionally, and especially in construction site environment, strategies to change workers' behaviours have focused on individual-level factors such as knowledge, beliefs, and skills. But as the need to raise the safety performance rises, intervention strategies have broadened to target factors at other levels of influence such as 
organisational policies and the built environment [68]. Specifically, to further improve the safety performance of construction industry, the need to introduce rules, procedure, laws and regulations by the government through its policies and programmes evolved. However, the interplay of numerous factors that determines the workers behaviours can make these efforts discouraging. A number of studies though not in construction industry have demonstrated that multifaceted community-based approaches that utilise an ecological model of intervention are more effective than single-strategy intervention approaches $[83,93,94]$. While the use of behavioural and social science theories in the context of injury prevention has been limited to a selected few [95], there are numerous examples of using behavioural, social and ecological approaches designed to promote safety in physical activity [96]. In injury prevention for example, the application of the ecological model in injury prevention has shown the most promise in falls injury prevention, road traffic injury prevention, and community safety promotion [42].

Even though there exists a plethora of frameworks of behaviour change interventions, it is not clear how well they serve this purpose [97]. There is also increasing support for the application of multi-faceted interventions to reduce falls among older adults [98]. Clemson et al [99] describe a multi-faceted community-based programme to reduce the incidence of falls in an elderly population [98]. Applying the ecological framework, Clemson et al [99] studied the impact of improving individual falls self-efficacy and lower-limb balance and strength, while improving home and communal environmental and behavioural safety. Moreover, an ecological approach that focuses on the multiple causative factors for falls, and policies that foster screening and referral programmes are most likely to succeed. The ecological model also takes into consideration the need to train personnel to conduct risk assessments, and preventive interventions [42].

Though there is dearth of research efforts in the direction of improving the safety performance of construction workers through SEM, DeJoy [100] proposed an integrative framework that conceptualises self-protective behaviour as consisting of four stages or phases: hazard appraisal, decision making, initiation, and adherence. In addition, five general constructs are identified as being of either primary or secondary importance at each stage: threat-related beliefs, response efficacy, self-efficacy, facilitating conditions, and safety climate. The proposed framework highlights the need to target interventions to each of the four stages. Particular emphasis was also assigned to environmental or situational factors in enabling and reinforcing self-protective behaviour in the workplace [100]. The study failed to recognise that behavioural change is more effective when systematically approach at multilevel perspective which SEM adequately addressed.

In addition, Michie, van Stralen and West [97] proposed a framework of behaviour change based on three essential conditions. According to Michie et al. [97], behaviour change occurs as an interaction between three necessary conditions: capability (psychological or physical ability to enact the behaviour); motivation (reflective and automatic mechanisms that activate or inhibit behaviour); and opportunity (physical and social environment that enables the behaviour). This change requires an appropriate method for characterising interventions and linking them to an analysis of the targeted behaviour [100]. Though this framework captures almost all the variables of SEM, it fails to recognise the multi-level interventions strategy for effective implementation. In view of these shortcomings therefore, the current study applies the principles of SEM to establish relationships between different attributes of SEM and safety performance of construction workers at multi-level interventions. This is with the acknowledgement that human factor plays a decisive role in most accidents, but the problems caused by them are still unresolved [101].

\section{Methodology}

This study is framed within a theoretical social ecological approach using McLeroy et al. [64] model of the social ecological levels to examine the influence of different safety behaviour interventions at different levels of SEM on the safety performance of construction workers. This approach provides a basis for physical activity research and practice, focussing attention on multiple issues, such as the social and physical environments, and policy implications [102]. Since construction process is an embodiment of physical activities, this approach is greatly suitable.

The study made use of questionnaire administered to randomly selected construction workers in one hundred and twelve (112) construction sites across some selected States in Nigeria. Parts of the consideration in the selection are the state's infrastructural development statues and geographical location, and the size and nature of construction site. The questionnaire was divided and structured into three parts. Part 1 captures the respondents' demographic data (the work trade, job position, nature of employment, site location, age of respondents, and years of experience). Part 2 contains forty (40) statements on information about the different safety behaviour interventions at five intervention levels of SEM. While part 3 measures the overall influence of safety behaviour intervention on the safety performance of construction workers with ten (10) structured statements. The respondents were asked to express their level of agreement on a five point Likert-type scale, where $1=$ strongly disagreed, and $5=$ strongly agreed.

With the help of associates and friends, the questionnaires were administered to 1,960 construction workers both in the management positions and operative (artisans) positions in the selected states. Out of this, a total 638 questionnaires were retrieved and used for analysis. This represents a response rate of $32.55 \%$ which was still good for this kind of study. Subsequently, the data generated through the questionnaire survey were subjected to descriptive and 
quantitative analysis using tables; mean score index and standard deviation. The Mean score Index was calculated.

Means score index is mathematically represented as:

$$
\mathrm{MS}=\frac{\sum \mathrm{fx}_{\mathrm{i}}}{\mathrm{N}}
$$

Where, MS is the mean score of each variable;

$\mathrm{f}$ is the frequency of responses to each rating;

$\mathrm{X}$ is the score or rating given to each variable by the respondents; and

$\mathrm{N}$ is the total number of responses concerning the variable.

To determine the degree to which these safety interventions influences the safety performance of construction workers, Pearson's Product-moment Correlation Coefficient(r) was used to establish the relationships between the different safety behaviour intervention variables and safety performance.

Pearson's Product-moment Correlation Coefficient (r) can be calculated using:

$$
r=\frac{n \sum x y-\sum x \sum y}{\sqrt{\left[n \sum x^{2}-\left(\sum x\right)^{2}\right]\left[n \sum y^{2}-\left(\sum y\right)^{2}\right]}}
$$

Where, $r=$ correlation coefficient;

$\mathrm{n}=$ number of pairs of variable being considered;

$\mathrm{x}=$ independent variable (culture dimensions); and

$\mathrm{y}=$ dependent variable (safety climate).

However the value of $r$ ranges from -1 for perfect negative correlation to +1 for perfect positive correlation. Subsequently, it is very important to ascertain whether the calculated correlation coefficient is statistically significant or not. This is done by using correlation significant test, with the test statistic ( $\mathrm{t}-$ test).This is calculated using:

$$
t=r \sqrt{\frac{n-2}{1-r^{2}}}
$$

Where $\mathrm{r}=$ correlation coefficient; and $\mathrm{n}=$ number of pairs of data.

The test is a two-tailed, non-directional test. However, in correlation significance test, the sign of the correlation coefficient is always assumed to be positive. The degree of freedom $(\mathrm{df})(\mathrm{n}-2)$ is used at $5 \%$ significant level. The mean values of both variables are used to get their correlation. When Pearson's Product-moment Correlation Coefficients (r) between the two variables were computed and their correlation coefficient test obtained at $(n-2)$ degree of freedom and 5\% $(\alpha=0.05)$ significant level.

Decision: Reject $\mathrm{H}_{0}$ if $\mathrm{t}_{\text {calculated }}>\mathrm{t}_{\text {critical }}$ at $\mathrm{df}(\mathrm{n}-2)$ and at $5 \%$ (0.05) significance level; otherwise accept $\mathrm{H}_{0}$ and conclude.

To establish the amount of variability in the safety performance attributed to the relationships to various safety behaviour intervention factors, the Coefficient of Determination $\left(\mathbf{R}^{2}\right)$ was calculated. This is the square of the Correlation Coefficient (r). Thus,

$$
\mathrm{R}^{2}=\mathrm{r}^{2}
$$

The results of the analysis are presented in the tables below.

\section{Results}

\subsection{Hypothesis}

$\mathbf{H}_{\mathbf{0}}$ : There is no significant relationship between safety behaviour intervention factors at different levels and safety performance of construction workers.

$\mathbf{H}_{\mathbf{1}}$ : There is significant relationship between safety behaviour intervention factors at different levels and safety performance of construction workers.

Table 1 presented the means, standard deviations and inter-correlations of all the variables concerned. The average mean scores of the variables ranged from 4.12 (for public policy) to 4.40 (for community). The high mean score suggested a high influence. Meanwhile, Bivariate correlations were performed to examine relationships between the concern variables. The result revealed that each of the variables has very strong positive correlation which was statistically significant at $5 \%$ significance level with each other. The strongest relationship occurred between organisational factors and public policy with a correlation coefficient (r) of 0.9996, while the least occurred between organisational factors and community factors with a correlation coefficient (r) of 0.9645 . However, all the variables were strongly correlated. In each case therefore, $\mathrm{p}<0.05$. This depicted that the variables influenced each other greatly and cannot work in isolation. It equally

\begin{tabular}{|c|c|c|c|c|c|c|c|c|c|}
\hline $\mathrm{S} / \mathrm{n}$ & Factor & Mean & Standard deviation & 1 & 2 & 3 & 4 & 5 & 6 \\
\hline 1 & Individual & 4.35 & 0.75 & 1 & & & & & \\
\hline 2 & Interpersonal & 4.26 & 0.80 & 0.9870 & 1 & & & & \\
\hline 3 & Organisational & 4.16 & 0.88 & 0.9763 & 0.9968 & 1 & & & \\
\hline 4 & Community & 4.40 & 0.67 & 0.9985 & 0.9782 & 0.9645 & 1 & & \\
\hline 5 & Public policy & 4.12 & 0.91 & 0.9780 & 0.9961 & 0.9996 & 0.9672 & 1 & \\
\hline 6 & Safety performance & 4.19 & 0.86 & 0.9821 & 0.9991 & 0.9990 & 0.9713 & 0.9986 & 1 \\
\hline
\end{tabular}
underscored the importance of their collective interplay in improving safety performance of construction workers.

Table 1. Means, standard deviations and inter-correlations of all the variables concerned

Correlation is significant at the 0.05 level (2-tailed), $\mathrm{N}=638, \mathrm{P}<0.05$ 
Table 2. Correlation of safety behaviour intervention factors and safety performance of construction workers

\begin{tabular}{|c|c|c|c|c|c|c|c|}
\hline $\begin{array}{c}\text { Safety behaviour Intervention } \\
\text { factors }\end{array}$ & $\begin{array}{c}\text { Correlation } \\
\text { Coefficient }(\mathrm{r})\end{array}$ & $\begin{array}{c}\text { Nature of } \\
\text { Association }\end{array}$ & $\begin{array}{c}\mathrm{T}-\text { test } \\
\text { value }\end{array}$ & $\begin{array}{c}\mathrm{T}_{\text {critical }} \\
(3,0.05)\end{array}$ & $\mathrm{R}^{2}$ & $\mathrm{P}$ - value & Decision \\
\hline Individual (intrapersonal) & 0.9821 & $\begin{array}{c}\text { Very strong } \\
\text { positive corr. }\end{array}$ & 9.031 & 3.182 & 0.9645 & 0.002867 & Reject $\mathrm{H}_{0}$ \\
\hline Interpersonal & 0.9991 & $\begin{array}{c}\text { Very strong } \\
\text { positive corr. }\end{array}$ & 40.797 & 3.182 & 0.9982 & 0.000032 & Reject $\mathrm{H}_{0}$ \\
\hline Organisational & 0.9990 & $\begin{array}{c}\text { Very strong } \\
\text { positive corr. }\end{array}$ & 38.701 & 3.182 & 0.9980 & 0.000038 & Reject $\mathrm{H}_{0}$ \\
\hline Community & 0.9713 & $\begin{array}{c}\text { Very strong } \\
\text { positive corr. }\end{array}$ & 7.073 & 3.182 & 0.9434 & 0.005811 & Reject $\mathrm{H}_{0}$ \\
\hline Public policy & $\begin{array}{c}\text { Very strong } \\
\text { positive corr. }\end{array}$ & 32.698 & 3.182 & 0.9972 & 0.000063 & Reject $\mathrm{H}_{0}$ \\
\hline
\end{tabular}

$\mathrm{df}=3 ; \alpha=0.05, P<0.05$.

Table 2 presented the results of correlation analysis of safety behaviour intervention factors and safety performance of construction workers. The results revealed that each of the five safety behaviour intervention factors (individual, interpersonal, organisational, community, public policy) based on the SEM, has very strong positive correlation of $0.9821,0.9991,0.9990,0.9713$ and 0.9986 with safety performance of construction workers respectively. This suggested that each of these factors could influence and promote greatly the safety performance of construction workers. This was attested when further regression analysis was performed. The values of the coefficient of determination $\left(\mathrm{R}^{2}\right)$ for each factor were as follows: (individual (0.9645), interpersonal (0.9982), organisational (0.9980), community $(0.9434)$, public policy $(0.9972))$. This implied that $96.04 \%, 99.82 \%, 99.80 \%, 94.34 \%$ and $99.72 \%$ safety performance improvement could be achieved when the each of the safety behaviour intervention factors were applied respectively.

When the correlation of each factor was tested for its significance at $5 \%$ significant level and degree of freedom of 3 , the results revealed that all the computed t-values (9.031, $40.797,38.701,7.073$ and 32.698) respectively were greater than the $t$-critical value (3.182) (i.e. $t_{\text {cal }}>t_{3,0.05}$ ). Likewise, the $\mathrm{p}$-values of all the factors were less than $0.05(\mathrm{p}<0.05)$ as can be seen in table 2. In view of this result, $\mathrm{H}_{0}$ was rejected in all cases and the study concluded that safety behaviour intervention factors at different levels are significantly related to the improved safety performance of construction workers. Moreover, the extent to which each of the p-values of the safety behaviour intervention factors were less than the critical p-value $(0.05)$ conforms to the degree of variability in the safety performance attributed to each of the factors as indicated by the values of the coefficient of determination.

\section{Discussion}

The results of this study showed that safety behaviour interventions were significantly related to the improved safety performance. This indicated that an increase in the safety behaviour intervention leads to improved safety performance and vice versa. Alternatively, it implied a decrease in unsafe behaviour when intervention was applied. This could also be translated to mean percentage accident reduction on site. The result of this study further implied that when positive safety behaviour intervention strategies are applied, safety performance of construction workers would be greatly improved. The percentage variability of each intervention factors signifies that with positive behaviour strategy at multi-level intervention, safety performance of construction workers would be improved. Although this model has not been applied in construction sector, the theoretical underpinnings of social ecology are relevant to several practical issues that arise in attempt to design effective industry-based safety behaviour interventions. For example, the challenge of developing safety performance improvement programmes that have enduring positive effects on safety behaviours of construction workers at all levels and avoid unintended adverse side effects is explicitly addressed in the safety performance improvement framework.

The result is consistent with the social ecological premise that both person and environment factors shape individual behaviours. The study also found that both individual personality characteristics and objective and subjective features of the individual's behaviour were robust correlates of safety interventions of how their behaviours affect their safety performance. Specifically, when the interventions were increased, workers would behave more safely thereby lowering the accident rates on site. The result also aligned with Jebb [47] who avers that as long as the outcomes for safety performance are not valued, or are inconsistently provided, or if outcomes for other performance metrics are more valued, or more consistently provided, the worker may experience conflicting motivations to perform safely. In this case, safety behaviour interventions must be motivating to be valued by the workers. The results are also consistent with the finding of Allegrante et al. [42] in accident reduction programme; $[64,66,69,81]$ in health promotion programme; $[85,96,99]$ in health behaviour change and improvement programme; and $[93,95,97]$ in fall and injury prevention programme even though they were in another fields of study.

\subsection{The Proposed Conceptual Framework}

The results of the correlation analysis in tables 1 and 2 
formed the basis for development of social ecological model of safety performance improvement framework. Figure 2 below shows the social ecological model of safety performance improvement. It further illustrates the interplay between all of the levels of the social ecological model and safety performance. The doted arrow represents the interrelationship between all the levels of SEM. This means that they act collectively in order to achieve the targeted goal. The horizontal arrows pointing at the safety behaviour intervention factors indicate the relationships between each of the factors with the safety performance (extent of influence on the safety performance). The fact that they are all pointing at safety behaviour intervention factors implies that they work in a pool to achieve improved safety performance. The interconnectivity of the different levels of intervention indicated that individual knowledge is not sufficient for behaviour change; rather increasing knowledge, training skills and creating a supportive environment are all important components of behaviour change. Therefore a programme cannot be implemented at one level without impacting on the other levels. Meanwhile, safety performance improvement through SEM in construction industry can be achieved through four (4) steps.

1 Acknowledging the existence of safety challenges on site: This involves identifying peculiar need for safety improvement at site. It is a specific individual challenges which affect the safety performance of the organisation and can affect the large community and other peoples around but can be moderated through policies and programme.

2 Identifying the intervention group: The next step is to identify which specific group(s) or situations is required to initiate the desired influence that can bring about improvement. In this case, different groups of people or situations are identified and modelled into the programme. For instance, individual (individual knowledge, skills, job position, sex, etc), interpersonal (family members, peers, co-workers, etc), organisational (organisational policy, leadership, communication channel, etc), community (social network, culture, work environment, norms, etc), and public policy (safety regulation, government policies and programme, etc).

3 Identifying the intervention mechanisms: This stage involves identifying the targeted strategies or actions that can be employed to achieve the targeted outcome. In this case, specific action(s) is identified at different intervention levels.

4 Implementing the intervention mechanisms: This is a call to action where different identified intervention groups would work individually and collectively in influencing the behaviours of the workers through different strategic means in ensuring the improvement of safety performance on site. For example applying the extant safety regulations by the government agencies concerned, pressure to meet the family needs, sanctioning of the erred worker by the organisation, etc.

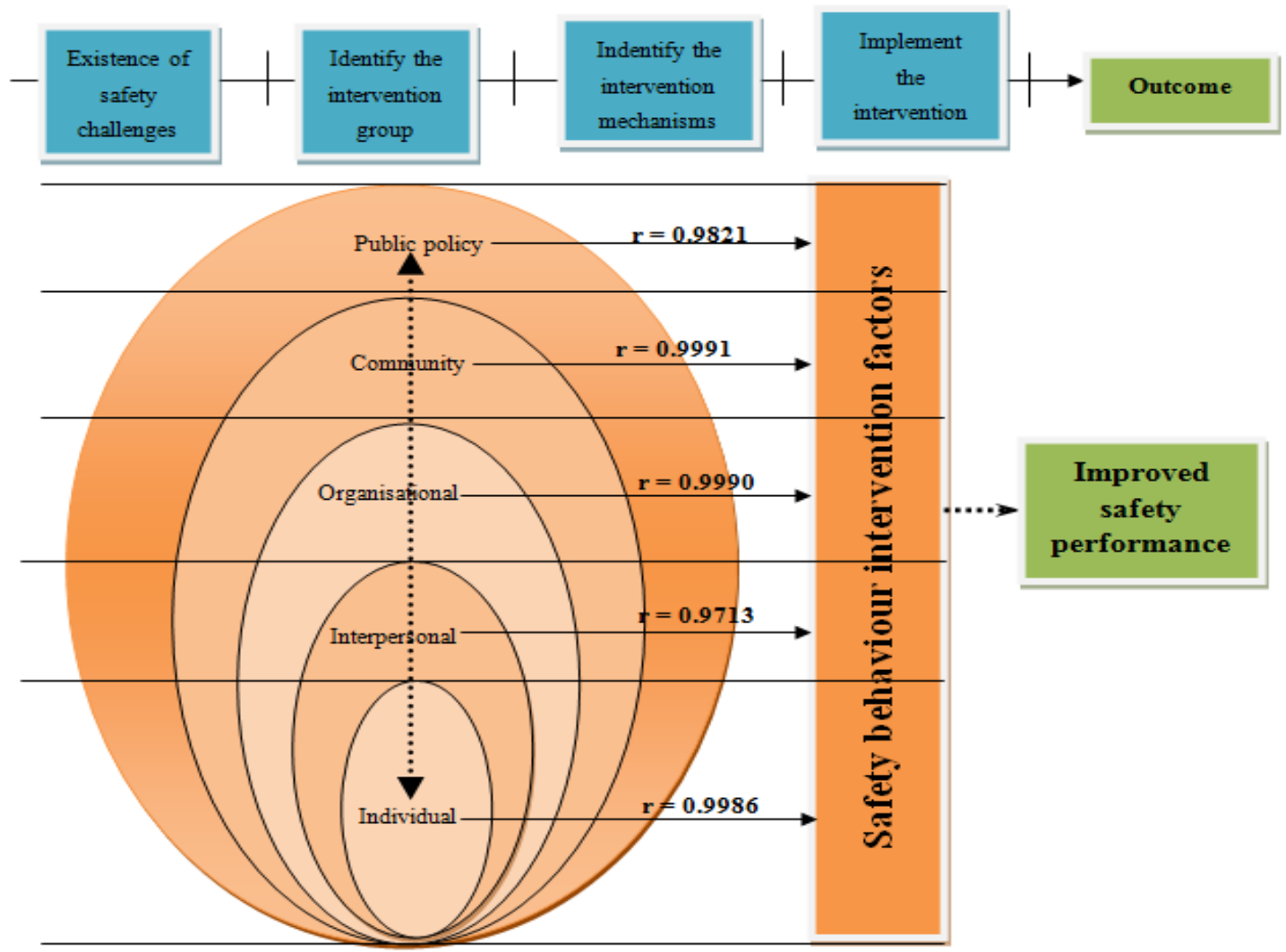

Figure 2. Social Ecological Model of Safety Performance Improvement (SEM-SPI) Framework 


\section{Conclusions}

Mechanistic approaches towards stepping down the rate of accidents on construction sites have seem to have yielded minimal results. Recent research $[97,100]$ has shown that the solution to improving safety performance of construction workers lies on the ability of workers to change their behaviours towards safety, thus shifting attention from mechanistic approach to a more behaviour based approach. In the search of means of safety improvement of construction industry, this study has adopted the Social Ecological Model as a framework for improvement of safety performance of construction workers. This is based on the fact that this approach has proved its worth in the public health and medical health research.

The study has successfully established that various safety behaviour intervention factors based on SEM were significantly related to improved safety performance of construction workers. The study further found that positive safety interventions lead to improved safety performance of construction workers. It also revealed that all the five safety behaviour intervention factors are very strongly correlated with the safety performance which in turn has influence on it. It then averred that though these factors individually influence the safety performance of construction workers, they cannot be separately applied in order to achieve the maximum improvement. The study developed a Social Ecological Model of Safety Performance Improvement framework through which safety can be improved in the construction industry. The framework is the platform through which safety can be improved on construction site. It identified five intervention levels based on the principles of SEM. The study also identified four strategic steps through which safety intervention could be implemented and applied through the framework.

The findings from this study highlighted a number of theoretical and practical implications for social ecological theory and practice. It has widened the scope of application of social ecological model to construction industry. This means that it added a new dimension in the application of social ecological theory. It has demonstrated that the behaviour of construction workers can be modelled into performing safely. The relationship established between the safety behaviour intervention factors and safety performance indicated that construction safety can be improved through positive behavioural change. In terms of novelty and contribution to the existing body of knowledge, the achievement of the study is phenomenal. It is the first study to apply the principal of SEM in safety improvement in the construction industry.

In the light of the significance of this study, the results from this study generated some compelling implications for policy, employment practice, and future research. The large, robust association found in this study between safety behaviour interventions and safety performance is particularly striking, given the current workplace realities and several efforts towards improving safety performance on construction sites across Nigeria. More importantly, the study empirically established relationships between safety behaviour intervention factors and safety performance which has given a strong footing for the development of social ecological model of safety performance improvement. It has exposed the dearth of research effort in this perspective and served as a call for more research in this area. First of its kind, the study developed social ecological model of safety performance improvement (SEM-SPI).

The study aimed to translate these research findings into applied recommendations for improving safety performance and related outcomes within the Nigeria construction industry. Therefore the study has provided resources for further research actions. Since safety is a capital issue in the Nigeria construction industry, the study recommended for practical application of the model for improvement of safety performance in the construction industry. This is because rules, regulations and managements systems have their role to play in improving safety performance, on their own they are inadequate to bring about further major improvements in safety performance which are required in the industry.

\section{REFERENCES}

[1] National Bureau of Statistics (NBS). Nigerian Construction Sector, Summary Report: 2010-2012, 2015a. Online available from www.nigeranstat.gov.ng.

[2] National Bureau of Statistics (NBS). Nigerian Gross Domestic Product Report, Quarter Four 2014, Issue 4, 2015 b. Online available from www.nigeranstat.gov.ng.

[3] National Bureau of Statistics (NBS). Nigerian Gross Domestic Product Report, Quarter Four 2015, Issue 8, 2016. Online available from www.nigeranstat.gov.ng.

[4] S. Laryea. Challenges and Opportunities Facing Contractors in Ghana, In: Laryea, S., Leiringer, R. and Hughes, W. (Eds), Proceedings of the West Africa Built Environment Research (WABER) Conference, Accra, Ghana, pp. 215-226, 27-28, July 2010. Online available from http//:www.centaur.reading.ac.uk/16282.

[5] F. Y. Y. Ling, M. F. Dulaimvmi, P. J. Ho. Strategies to Overcome Challenges Faced in Managing Construction Projects in The United Arab Emirates, World Construction Conference 2012 - Global Challenges in Construction Industry, Colombo, Sri Lanka, pp. 229-236, 2012.

[6] N. I. Hashim, N. Chileshe, B. Baroudi. Management Challenges within Multiple Project Environments: Lessons for Developing Countries, Australasian Journal of Construction Economics and Building, Conference Series, Vol. 1, No. 2, pp. 21-31, 2012.

[7] P. U. Okoye, C. Ngwu, S. C. Ugochukwu. Evaluation of Management Challenges Facing Construction Practice in Nigeria, International Journal of Application or Innovation in Engineering \& Management (IJAIEM), Vol. 4, No. 1, January, pp. 19-28, 2015. Online available from www.ijaiem.org. 
[8] J. Lunt, S. Bates, V. Bennett, J. Hopkinson. Behaviour Change and Worker Engagement Practices within the Construction Sector, Research Report of Health and Safety Executive, RR660, 2008.

[9] J. W. Hinze. Construction Safety. Prentice Hall Publications, New Jersey, 1997.

[10] G. L. Janackovic1, S. M. Savic, M. S. Stankovic. Selection and Ranking of Occupational Safety Indicators Based on Fuzzy AHP: A Case Study in Road Construction Companies, South African Journal of Industrial Engineering, Vol. 24, No. 3, November, pp. 175-189, 2013. .

[11] X. Huang, J. Hinze. Owner's Role in Construction Safety. Journal of Construction Engineering and Management, Vol. 132 No. 2, pp. 164-173, 2006.

[12] S. Z. Alkilani, J. Jupp, A. Sawhney. Issues of Construction Health and Safety in Developing Countries: A Case of Jordan, Australasian Journal of Construction Economics and Building, Vol. 13, No. 3, pp. 141-156, 2013.

[13] K. Mouleeswaran. Evaluation of Safety Performance Level of Construction Firms in and Around Erode Zone, International Journal of Innovative Research in Science, Engineering and Technology, Vol. 3, Special Issue 1, January, pp. 1586-1594, 2014. Online available from www.ijirset.com.

[14] V. Sousa, N. Almeida, L. Dias. Risk-based management of occupational safety and health in the construction industry Part 1: Background knowledge. Safety Science, Vol. 66, pp. 75-86, July, 2014.

[15] I. Mosly. Safety Performance in the Construction Industry of Saudi Arabia, International Journal of Construction Engineering and Management, Vol. 4, No. 6, pp. 238-247, 2015. DOI: $10.5923 /$ j.ijcem.20150406.03.

[16] W. Jill, H. John. Promoting Construction Health and Safety through Procurement: A Briefing Note for Developing Countries, Institution of Civil Engineers, 2010.

[17] International Labour Organisation (ILO). The Role of Worker Representation and Consultation in Managing Health and Safety in the Construction Industry. Geneva, 2010.

[18] Occupational Safety and Health Administration (OSHA). Injury and Illness Prevention Programs, White Paper, 2012. Online available from http://www.osha.gov/dsg/topics/safety health/OSHAwhite-paper-january2012sm.pdf.

[19] International Labour Organisation (ILO). Safety in Numbers Pointers for Global Safety Culture at Work, 2003. Online available from http://www.ilo.org/wcmsp5/groups/public/--edprotect/---protrav/---safework/documents/publication/wcm s_142840.pdf.

[20] J. McKenzie, A. G. F. Gibb, N. M. Bouchlaghem. Communication of Health and Safety in Design Phase: Implementation of Safety and Health on Construction Sites, Proceedings of the 2nd International Conference of International Council for Research and Innovation in Building and Construction (CIB) Working Commission W99, Honolulu, pp. 419-426, 1999.

[21] C. R. Che Hassan, O. J. Basha, W. H. Wan Hanafi. Perception of Building Construction Workers towards Safety, Health and Environment, Journal of Engineering Science and Technology, Vol. 2, No. 3, pp. 271 -279, 2007.
[22] Bomel Ltd. Improving Health and Safety in Construction Phase 1: Data Collection, Review and Structuring, Contract Research Report 386/2001. HSE Books, Sudbury, 2001.

[23] Health and Safety Executive (HSE). Statistics on Fatal Injuries in the Workplace in Great Britain, 2015: Full-Year Details and Technical Notes, 2015a. Online available from www.hse.gov.uk/statistics/fatals.htm.

[24] Health and Safety Executive (HSE). Health and Safety in Construction Sector in Great Britain, 2014/2015, 2015 b. Online available from www.hse.gov.uk/statistics/industry/co nstruction/construction.pdf.

[25] L. H. Siang, A. Tan. Singapore's Framework for Reporting Occupational Accidents, Injuries and Diseases, African Newsletter on Occupational Health and Safety, Vol. 20, No. 3, pp. 57-60, 2010. Online available from http://www.ttl.fi/AfricanNewsletter.

[26] W. A. Asanka, M. Ranasinghe. Study on The Impact Of Accidents on Construction Projects, 6th International Conference on Structural Engineering and Construction Management, Kandy, Sri Lanka, pp. 58-67, 11th - 13th December, 2015.

[27] M. R. Hosseini, M. Maghrebi, R.Rameezdeenc, S . T. Waller. Statistically Reviewing Construction Accidents within South Australia during 2002-2013. Proceedings of ISARC15, 2015

[28] General Organisation for Social Insurance (GOSI). Annual statistical report $1435 \mathrm{H}, 2015$. Online available from http://www.gosi.gov.sa/portal/web/guest/statistics/view-stat istic?StatisticsId=1379226.

[29] A. Pinto, I. Nunes, R. Ribeiro. Occupational Risk Assessment in Construction Industry-Overview and Reflection, Safety Science, Vol. 49, No. 5, pp. 616-624, 2011.

[30] P. Wadick. Safety Culture among Subcontractors in the Domestic Housing Construction Industry, Structural Survey, Vol. 28, No. 2, pp. 108-120, 2010.

[31] A. Al-Wreidat. The National Occupational Safety and Health Profile of the Hashemite Kingdom of Jordan, The Report of Ministry of Labour, Directorate of Occupational Safety and Health in Collaboration with International Labour Organisation, Amman, Jordan, 2006.

[32] K. Somasundaraswaran, T. Brammananda, J.A. Akeel, G. Rajakumar. Evaluation of Safety Level at Construction Sites in Sri Lanka, Proceedings of the Third Academic Sessions, pp. 148-153, 2005.

[33] R. Irumba. Modelling of Construction Safety Performance and Housing Markets in Kampala City, Uganda, Doctoral Thesis Building and Real Estate Economics, Department of Real Estate and Construction Management, KTH Royal Institute of Technology, Stockholm, 2015.

[34] J. Smallwood, T. Haupt, W. Shakantu. Construction Health \& Safety in South Africa, Research report undertaken by Construction Research Education and Training Enterprises (CREATE), Construction Industry Development Board (CIDB), pp. 1-48, 2010. Online available from www.cidb.org.za.

[35] U. Abubakar. An Overview of the Occupational Safety and Health Systems of Nigeria, UK, USA, Australia and China: Nigeria Being the Reference Case Study. American Journal of Educational Research, Vol. 3, No. 11, pp. 1350-1358, 2015. 
DOI: 10. 12691/education-3-11-3.

[36] P. Hämäläinen, K. L. Saarela, J. Takala. Global Trend According to Estimated Number of Occupational Accidents and Fatal Work-Related Diseases at Region and Country Level, Journal of Safety Research, Vol. 40, No. 2, pp. 125-139, 2009.

[37] N. Umeokafor, K. Evaggelinos, S. Lundy, D. Isaac, S. Allan, O. Igwegbe, K. Umeokafor, B. Umeadi. The Pattern of Occupational Accidents, Injuries, Accident Causal Factors and Intervention in Nigerian Factories. Developing Country Studies, Vol. 4, No. 15, pp. 119-127, 2014.

[38] U. Abdulahi, I. Anum, A. M. Adole, F. N. Williams. Artisans Working Conditions in the Nigerian Construction Industry: A Case Study of Some States in Northern Nigeria, ATBU Journal of Environmental Technology, Vol. 8, No. 1, pp. 16-25, 2015.

[39] J. M. Matiko. Injury and Disease Reporting in Tanzania, African Newsletter on Occupational Health and Safety, Vol. 20, No. 3, pp. 48-50, 2010. Online available from http://www.ttl.fi/AfricanNewsletter.

[40] B. Talabi, F. Edum-Fotwe, A. Gibb. Construction Actor Safety Behaviour: Antecedents, Current Thinking and Directions, In: Smith, S. D. and Sherratt, F. (eds). Proceeding of ARCOM Doctoral Workshop, Health, Safety and Wellbeing, University of Edinburgh, pp. 9-20, 11th February 2015. Online available from https://dspace.lboro.ac.uk/2134/ 17340 .

[41] M. Fleming, N. Scott. Assessing Employee Safety Motivation. Focus on Tomorrow, Research Funded by Work Safe BC and Workers' Compensation Board of Nova Scotia, RS2010-DG08, 2012.

[42] J. P. Allegrante, D. W. Hanson, D. A. Sleet, R. Marks. Ecological Approaches to the Prevention of Unintentional Injuries, Italian Journal of Public Health, JPH-year 8, Vol. 7, No. 2, pp. 24-31, 2010.

[43] K. Priyadarshani, G. Karunasena, S. Jayasuriya. Construction Safety Assessment Framework for Developing Countries: A Case Study of Sri Lanka, Journal of Construction in Developing Countries, Vol. 18, No. 1, pp. 33-51, 2013.

[44] G. Hoyos. Occupational Safety: Progress in Understanding the Basic Aspects of Safe and Unsafe Behaviours, Applied Psychology, An International Review, Vol. 44, pp. 233- 250, 1995.

[45] H.W. Guo, T. W. Yiu. How Traditional Construction Safety Performance Indicators Fail To Capture the Reality of Safety, AUBEA 2013 Programme, 2013.

[46] T. R. Lee. The Role of Attitudes in the Safety Culture and how to Change them, Paper presented at the Conference on 'Understanding Risk Perception'. Aberdeen: Offshore Management Centre, The Robert Gordon University, 1995.

[47] S. Jebb. Reducing Workplace Safety Incidents: Bridging The Gap Between Safety Culture Theory and Practice, Doctor of Philosophy Thesis, Centre for Accident Research and Road Safety, School of Psychology and Counselling Institute of Health and Biomedical Innovation, Faculty of Health, Queensland University of Technology, 2015.

[48] M. Dejoy. Behaviour Change versus Culture Change: Divergent Approaches to Managing Workplace Safety,
Safety Science, Vol. 43, pp. 105-129, 2005.

[49] R. B. McAfee, A. R. Winn. The use of Incentives/Feedback to Enhance Workplace Safety: A Critique of the Literature, Journal of Safety Research, Vol. 20, pp. 7-19, 1989.

[50] W. Guldenmund. Understanding and Exploring Safety Culture. (Published Dissertation). Oisterwijk, Netherlands, UitgeverijBoxpress, 2010.

[51] S. Wamuziri. Improving Safety Performance in Construction through Cultural Change. In: Dainty, A (Ed) Proceedings of 24th Annual ARCOM Conference, Cardiff, UK, Association of Researchers in Construction Management, pp. 1103-1112, 1-3 September 2008.

[52] F. Sherratt. Exploring 'Zero Target' Safety Programmes in the UK Construction Industry. Construction Management and Economics, Vol. 32, No. 7-8, pp. 737-748, 2014.

[53] K. Glanz, B. D. Bishop. The Role of Behavioural Science Theory in Development and Implementation of Public Health Interventions, Annual Review of Public Health, Vol. 31, pp. 399-418, 2010. doi:10.1146/annurev.publhealth.012809.103 604.

[54] Y. Khosravi, H. Asilian-Mahabadi, E. Hajizadeh, N. Hassanzadeh-Rangi, A. H. Behzadan. Structural Modeling of Safety Performance in Construction Industry, Iranian Journal of Public Health, Vol. 43, No.8, pp. 1099-1106, 2014. Online available from http://ijph.tums.ac.ir.

[55] B. Sulzer-Azaroff, J. Austin. Does BBS Work? Behaviour-Based Safety and Injury Reduction: A Survey of the Evidence, Professional Safety, Vol. 45, No. 7, pp. 19-24, 2000.

[56] E. S. Geller. Psychological Science and Safety: Large-scale Success at Preventing Occupational Injuries and Fatalities, Current Directions in Psychological Science, Vol. 20, No. 2, pp. 109-114, 2011.

[57] D. Cooper. The Return on Investment of the B-BS Process, GiornaleItaliano di Medicina del LavoroedErgonomia, Vol. 32, No. 1, pp. A15-A17, 2010.

[58] J. Hovden, E. Albrechtsen, I. A. Herrera. A need for New Theories, Models and Approaches to Occupational Accident Prevention? Working on Safety Conference, Crete, Hellas, 30 September -3 October, 2008.

[59] D. X. Henderson, T. D. Baffour. Applying a Socio-Ecological Framework to Thematic Analysis Using a Statewide Assessment of Disproportionate Minority contact in the United States, The Qualitative Report, Vol. 20, No. 12, pp. 1960-1973, 2015. Online available from http://nsuworks.nova.edu/tqr/vol20/iss12/2.

[60] Victorian Curriculum and Assessment Authority (VCAA). Social Ecological Model, VCE Physical Education (2011-2014), Unit 3, 2010.

[61] World Health Organisation (WHO). Ottawa Charter for Health Promotion, Geneva, Switzerland, 1986. Online available from www.who.int/hpr/NPH/docs/ottawa_charter_ hp.pdf.

[62] K. Glanz, B. K. Rimer, K. Viswanath. (Eds.). Health Behaviour and Health Education: Theory, Research, and Practice, (4th ed), San Francisco: Jossey-Bass, 2008. 
[63] U. Bronfenbrenner. The Ecology of Human Development: Experiments by Nature and Design, Harvard College, United States of America, 1979.

[64] K. McLeroy, D. Bibeau, A. Steckler, K. Glanz. An Ecological Perspective on Health Promotion Programs, Health Education \&Behaviour, Vol. 15, No. 4, pp. 351-377, 1988.

[65] D. Stokols. Establishing and Maintaining Healthy Environments: Toward a Social Ecology of Health Promotion, American Psychologist, Vol. 47, No. 1, pp. 6-22, 1992.

[66] D. Stokols. Translating Social Ecological Theory into Guidelines for Community Health Promotion, American Journal of Health Promotion, Vol. 10, pp. 282-298, 1996.

[67] D. Stokols, J. G. Grzywacz, S. McMahan, K. Phillips. Increasing the Health Promotive Capacity of Human Environments, American Journal of Health Promotion, Vol. 18, No. 1, pp. 4- 13, 2003.

[68] K. Glanz. Social and Behavioural Theories, Behavioural \& Social Science Research, e-Source, 2010.

[69] B. D. Smedley, S. L. Syme. Promoting Health: Intervention Strategies from Social and Behavioural Research, American Journal of Health Promotion, Vol. 15, pp. 149-166, 2001.

[70] A. Bandura. Organisational Application of Social Cognitive Theory, American Journal of Management, Vol. 13, No. 2, pp. 275-302 1988.

[71] A. Bandura. Social Cognitive Theory: An Agentic Perspective, Annual Reviews Psychologist, Vol. 52, pp. 1-26, 2001.

[72] A. Bandura. Social Cognitive Theory in Cultural Context, Applied Psychology, An International Review, Vol. 51, No. 2, pp. 269-290, 2002.

[73] S. L. Brown. Using a Social-Ecological Model to Examine Obesity Interventions, Graduate Theses and Dissertations. Paper 10440, Digital Repository, Iowa State University, 2011. Online available from http://lib.dr.iastate.edu/etd.

[74] U. Bronfenbrenner. Ecological Models of Human Development, In International Encyclopaedia of Education, Elsevier, Oxford, UK, pp. 37- 42, 1994.

[75] K. Callahan-Myrick. Assessing the Social and Ecological Factors that Influence Childhood Overweight and Obesity, A $\mathrm{PhD}$ Dissertation, Faculty of the College of Public Health, East Tennessee State University, 2014.

[76] J. D. Langille, W. M. Rodgers. Exploring the Influence of a Social Ecological Model on School-Based Physical Activity, Health Education and Behaviour, Vol. 37, No. 6, 879-894, 2010. doi: $10.1177 / 1090198110367877$.

[77] J. P. Elder, L. Lytle, J. F. Sallis, D. R. Young, A. Steckler, D. Simons-Morton, E. Stone, J. B. Jobe, J. Stevens, T. Lohman, L. Webber, R. Pate, B. I. Saksvig, K. Ribisl. A Description of the Social-Ecological Framework used in the Trial of Activity for Adolescent Girls (TAAG), Health Education Research, Vol. 22, No.2, pp. 55-165, 2007. doi:10.1093/her/cyl059.

[78] R. Lakhan, O. T. Ekúndayò. Application of the Ecological Framework in Depression: An Approach whose Time has come, AP J Psychological Medicine Vol. 14, No. 2, 103-109, 2013.
[79] N. Sarrafzadegan, K. Rabeie, F. Nouri, N. Mohammadifard, F. Moatter, H. Roohafza, M. Pourmoghaddas. Parental Perceptions of Overweight and Obesity of their Children, ARYA Atheroscler, Vol. 9, No. 1, pp. 61-69, 2013.

[80] Institute of Medicine. Who will keep the Public Healthy? Educating Public Health Professionals for the 21st Century, The National Academies Press, Washington, DC, 2003.

[81] G. Kok, N. H. Gottlieb, M. Commers, C. Smerecnik. The Ecological Approach in Health Promotion Programs: A Decade Later, American Journal of Health Promotion, 22, pp. 437-442, 2008.

[82] J. Fleury, S. Lee. The Social Ecological Model and Physical Activity in African American women, American Journal of Community Psychology, Vol. 37, No. 1/2, pp. 129-140, 2006.

[83] E. Richards, M. E. Riner, L. P. Sands. A Social Ecological Approach of Community Efforts to Promote Physical Activity and Weight Management, School of Nursing Faculty Publications, Paper 3, 2008. Online available from http://dx.doi.org/10.1080/07370010802421145.

[84] P. T. Katzmarzyk, L. A. Baur, S. N. Blair, E. V. Lambert, J. M. Oppert, C. Riddoch. International Conference on Physical Activity and Obesity in Children: Summary Statement and Recommendations, Applied Physiology Nutrition and Metabolism, vol. 33, pp. 371-387, 2008.

[85] J. F. Sallis, N. Owen, E. B. Fisher. Ecological Models of Health Behaviour. In Glanz, K. Rimer, B. K. Viswanath, K. (Eds.), Health Behaviour and Health Education: Theory, Research, and Practice, 4th Edition: Theory, Research, and Practice (Google eBook). Jossey-Bass, San Francisco, CA, pp. 465-485, 2008.

[86] M. S. Jamner, D. Stokols. Promoting Human Wellness: New Frontiers for Research, Practice and Policy, University of California Press, Berkley, USA, 2000.

[87] A. Boyce, D. H. Olster. Strengthening the Public Research Agenda for Social Determinants of Health, American Journal of Preventive Medicine, Vol. 40, pp. 86-8, 2011.

[88] N. Melgar. M. Rossi. A Cross-Country Analysis of the Risk Factors for Depression at the Micro and Macro Levels, American Journal of Economics and Sociology Vol. 71, No. 2, pp. 354-376, 2012.

[89] D. Storey, M. E. Figueroa. Toward a Global Theory of Health Behaviour and Social Change, In R. Obragon and S. Waisbord (eds), the HandBook of Global Health Communication, John Willy \& Sons. Inc, 2012.

[90] P. R. Smokowski, C. B. R. Evans, K. Cotter, S. Guo. Ecological Correlates of Depression and Self-Esteem in Rural Youth, Journal of Child Psychiatry and Human Development. Online First, 2013. doi:10.1007/s10578-013-0420-8.

[91] M. S. Terry. Applying the Social Ecological Model to Violence against Women with Disabilities, Journal of Women's Health Care, Vol. 3, No 6, p. 193, 2014. doi:10.4172/2167-0420.1000193.

[92] V. L. N. Schölmerich, I. Kawachi. Translating the Social-Ecological Perspective into Multilevel Interventions for Family Planning: How Far are we? Health Education \& Behaviour, pp. 1-10, 2016. DOI:10.1177/10901981166294 42. 
[93] A. E. Dyer, G. J. Taylor, M. Reed. C. A. Dyer, D. R. Robertson, R. Harrington. Falls Prevention in Residential Care Homes: A Randomised Controlled Trial, Age Aging, Vol. 33, pp. 596-602, 2004

[94] K. G. Tidball, M. E. Krasny. Urban Environmental Education from a Social-Ecological Perspective: Conceptual Framework for Civic Ecology Education, Cities and the Environment, Vol. 3, No. 1, article 11, pp. 1-20, 2010. Online available from http://escholarship.bc.edu/cate/vol3/iss1/11.

[95] L. B. Trifiletti, A. C. Gielen, D. A. Sleet, K. Hopkins. Behavioural and Social Sciences Theories and Models: Are they used in Unintentional Injury Prevention Research? Health Education Research, Vol. 20, pp. 298-307, 2005.

[96] P. Winch. Ecological Models and Multilevel Interventions, Health Behaviour Change at the Individual, Household and Community Levels, Johns Hopkins Bloomberg School of Public Health, pp. 224.689, 2012.

[97] S. Michie, M. M. van Stralen, R. West. The Behaviour Change Wheel: a New Method for Characterising and Designing Behaviour Change Interventions, Implementation Science, Vol. 6, No. 42, 23 Apr, 2011. Doi:10.1186/1748-5908-6-42.
[98] R. Marks, J. P. Allegrante. Falls Prevention Programs for Older Ambulatory Community Dwellers: From Public Health Research to Health Promotion Policy, Soz Preventive medicine, Vol. 49, pp. 171-178, 2004.

[99] L .Clemson, R. G. Cumming, H. Kendig, M. Swann, R. Heard, K. Taylor. The Effectiveness of a Community-Based Program for Reducing the Incidence of Falls in the Elderly: A Randomised Trial, Journal of American Geriatric Sociology, Vol. 52, pp. 1487-94, 2004.

[100] M. DeJoy. Theoretical Models of Health Behaviour and Workplace Self-Protective Behaviour, Journal of Safety Research, Vol. 27, No. 2, pp. 61-72, 1996.

[101] I. Fedorycheva, M. Hammer. A Description of Safety Triad Models of Safety Culture as a Tool in Human Performance Research, Mm Science Journal, pp. 768-771, December, 2015. DOI:10.17973/MMSJ.2015_12_201559.

[102] B. Giles-Corti. People or Places: What should be the Target? Journal of Science and Medicine in Sport, Vol. 9, pp. 357-366, 2006. 